\title{
Evaluation of the GenoType Mycobacterium Assay for Identification of Mycobacterial Species from Cultures
}

\author{
Elvira Richter, Sabine Rüsch-Gerdes, and Doris Hillemann* \\ Forschungszentrum Borstel, National Reference Center for Mycobacteria, D-23845 Borstel, Germany
}

Received 27 October 2005/Returned for modification 2 December 2005/Accepted 11 March 2006

\begin{abstract}
A new commercially available DNA strip assay (GenoType Mycobacterium CM/AS; Hain Lifescience, Nehren, Germany) was evaluated for the ability to differentiate mycobacterial species. The test is based on a PCR technique targeting a 23S rRNA gene region, followed by reverse hybridization and line probe technology. The GenoType CM is capable of identifying 23, the GenoType AS a further 14, species either alone or in combination with one or more species. Both tests were evaluated with 156 mycobacterial strains composed of 61 validly published species including different subspecies, 6 not validly published species, and 3 strains other than mycobacterial species. All strains were precharacterized by sequencing of the $5^{\prime}$ region of the 16S rRNA gene and biochemical tests. In total, results for 151 strains were interpretable. Concordant results were obtained for $137(92.6 \%)$ of 148 mycobacterial strains with the CM assay and $133(89.9 \%)$ of 148 mycobacterial strains with the AS assay, and all three non-Mycobacterium species were identified.
\end{abstract}

In recent years, the number of validly described mycobacterial species has increased markedly. The reasons for this are manifold, as some species such as Mycobacterium genavense have newly been identified in immunosuppressed patients, but also include improved culture and detection techniques.

The identification of mycobacteria responsible for a disease and the discrimination of environmental from pathogenic species are relevant diagnostic issues that have important ramifications for the treatment of patients $(14,30)$. Since identification to the species level of more than 100 mycobacterial species by classical biochemical methods is too time-consuming and error prone, the introduction of molecular biological methods has greatly improved the speed and accuracy of the process. New DNA sequence-based techniques for the identification of mycobacteria have been developed during the past 10 years, such as DNA sequencing $(3,4,11)$, pyrosequencing (29), PCR-restriction fragment length polymorphism assays $(6,26,27)$, real-time PCR assays (21), oligonucleotide arrays (10), and commercially available tests such as the AccuProbe (Gen-Probe Inc., San Diego, Calif.). Most of these methods require either expensive equipment or extensive expert knowledge or are restricted to a limited number of species that can be identified.

Recently, DNA strip assays for the identification of mycobacteria to the species level have been developed, i.e., the INNO-LiPA MYCOBACTERIA v2 (Innogenetics N.V., Ghent, Belgium) and GenoType Mycobacterium (Hain Lifescience $\mathrm{GmbH}$, Nehren, Germany) assays. These assays are based on reverse hybridization of a PCR product to a nitrocellulose strip with immobilized probes for different mycobacterial species. The INNO-LiPA MYCOBACTERIA v2 assay targets the 16S-to-23S rRNA gene spacer region and provides the identification of 16 different species, whereas the GenoType assay, targeting the $23 \mathrm{~S}$ rRNA gene region, provides the simul-

* Corresponding author. Mailing address: Forschungszentrum Borstel, National Reference Center for Mycobacteria, Parkallee 18, D-23845 Borstel, Germany. Phone: (49)-4537-188761. Fax: (49)-4537188311. E-mail: dhillemann@fz-borstel.de. taneous identification of 13 different mycobacterial species. Some evaluation studies have demonstrated the usefulness of both assays for the easy and rapid identification of the majority of common mycobacteria isolated from clinical specimens $(7,9,19,20)$.

In order to broaden the detection range of mycobacterial species, a new version of the GenoType assay (also targeting the 23S rRNA gene) has been developed, i.e., the combined GenoType Mycobacterium CM/AS assays (CM, common mycobacteria; AS, additional species), which are executed consecutively. The CM assay enables the simultaneous identification of species, including the most relevant $M$. tuberculosis complex, members of the M. avium complex, M. kansasii, and M. chelonae. Additionally, the second (AS) test provides the identification of species that are found more infrequently, such as $M$. simiae, M. mucogenicum, and M. celatum. Thus, serial use of the two strips is aimed to identify 35 different patterns, of which 23 patterns can be assigned to single species, 8 patterns are allocated to two or more Mycobacterium species, and 4 patterns correspond to Mycobacterium species and gram-positive bacteria with a high $\mathrm{G}+\mathrm{C}$ content.

The objective of this study was to assay whether a variety of relevant mycobacterial strains correctly match the GenoType Mycobacterium CM/AS pattern by investigating 156 strains composed of 83 different species or subspecies. These strains, all identified to the species level, were selected to represent a broad variety of strains. The applicability of the assay in a mycobacterial routine laboratory is discussed.

\section{MATERIALS AND METHODS}

Strains analyzed. A set of 156 clinical isolates derived from different patients $(n=153)$ or cows $(n=3)$ between 1999 and 2004 was analyzed (Table 1$)$. The samples were selected by the following criteria. At least two strains of all species that are detectable with any of the assays were included and tested with both the $\mathrm{CM}$ and AS assays. If available, at least two samples of subspecies were selected for the tests. Furthermore, strains that were not detectable with both assays were also included. These strains were composed of validly published mycobacterial species, other mycobacterial strains characterized only by their 16S rRNA gene sequences, and some other closely related species of the genera Corynebacterium, Nocardia, and Rhodococcus (Table 1). 
TABLE 1. Identification of mycobacteria by GenoType Mycobacterium CM and AS assays

\begin{tabular}{|c|c|c|c|c|c|}
\hline \multirow{2}{*}{$\begin{array}{l}\text { Mycobacterium } \\
\text { species }^{a}\end{array}$} & \multirow{2}{*}{$\begin{array}{l}\text { No. of } \\
\text { strains }\end{array}$} & \multicolumn{2}{|c|}{ GenoType CM results } & \multicolumn{2}{|c|}{ GenoType AS results } \\
\hline & & Band pattern ${ }^{k}$ & Identification & Band pattern ${ }^{k}$ & Identification \\
\hline M. tuberculosis complex ${ }^{b}$ & 14 & $1,2,3,10,16$ & M. tuberculosis complex & $1,2,3$ & Mycobacterium sp. \\
\hline M. avium $^{c}$ & 5 & $1,2,[3], 4$ & M. avium subsp. & $1,2,[3]$ & Mycobacterium $\mathrm{sp}$. \\
\hline M. chelonae & 2 & $1,2,3,5,10$ & M. chelonae-M. immunogenum & $1,2,3,12$ & Mycobacterium sp. \\
\hline M. immunogenum & 2 & $1,2,3,5,6,10$ & M. abscessus-M. immunogenum & $1,2,3,12$ & Mycobacterium sp. \\
\hline M. abscessus & 2 & $1,2,3,5,6,10$ & M. abscessus-M. immunogenum & $1,2,3,12$ & Mycobacterium $\mathrm{sp}$. \\
\hline M. fortuitum & 3 & $1,2,3,7,14$ & M. fortuitum & $1,2,3$ & Mycobacterium sp. \\
\hline M. fortuitum & 1 & $1,2,7,14$ & M. fortuitum & $1,2,(6),(14)$ & $\begin{array}{l}\mathrm{Gram}^{+}, \text {high } \mathrm{G}+\mathrm{C} \text { content }^{j} \\
\quad(\text { M. smegmatis })\end{array}$ \\
\hline M. fortuitum & 2 & $1,2,3,7$ & $M$. fortuitum-M. mageritense & $1,2,3$ & Mycobacterium sp. \\
\hline M. mageritense & 1 & $1,2,3,7$ & $M$. fortuitum-M. mageritense & $1,2,3$ & Mycobacterium $\mathrm{sp}$. \\
\hline M. gordonae ${ }^{d}$ & 7 & $1,2,3,8,10$ & M. gordonae & $1,2,3$ & Mycobacterium $\mathrm{sp}$. \\
\hline M. gordonae II & 1 & $1,2,3,8,10$ & M. gordonae & $1,2,3,12$ & Mycobacterium sp. \\
\hline M. intracellulare $e^{e}$ & 7 & $1,2,[3], 9$ & M. intracellulare & $1,2,[3]$ & Mycobacterium sp. \\
\hline M. intracellulare serovar 7 & 1 & $1,2,3$ & Mycobacterium sp. & $1,2,3$ & Mycobacterium sp. \\
\hline M. scrofulaceum & 2 & $1,2,[3], 9,10$ & M. scrofulaceum-"M. paraffinicum" & $1,2,[3], 12$ & Mycobacterium $\mathrm{sp}$. \\
\hline "M. paraffinicum" & 2 & $1,2,3,9,10$ & M. scrofulaceum-"M. paraffinicum" & $1,2,3,12$ & Mycobacterium sp. \\
\hline M. interjectum & 1 & $1,2,3,(9), 10,11$ & $M$. interjectum & $1,2,3,12$ & Mycobacterium sp. \\
\hline M. kansasii ${ }^{f}$ & 4 & $1,2,[3],(9), 10,12$ & M. kansasii & $1,2,[3], 10,12$ & M. kansasii \\
\hline M. kansasii III and VI & 2 & $1,2,[3],(9), 10,12$ & M. kansasii & $1,2,[3], 9,10,12$ & $\begin{array}{l}\text { Mycobacterium sp., pattern } \\
\text { not attributable }\end{array}$ \\
\hline M. kansasii VI & 1 & $\begin{array}{l}1,2,3,(9), 10 \\
(12,13)\end{array}$ & $\begin{array}{l}\text { Mycobacterium sp., pattern not } \\
\text { attributable }\end{array}$ & $1,2,3,(10,12)$ & $\begin{array}{l}\text { Mycobacterium } \mathrm{sp} . \\
\quad(\text { M. kansasii })\end{array}$ \\
\hline M. malmoense & 2 & $1,2,3,10,13$ & $\begin{array}{l}\text { M. malmoense- } M \text {. haemophilum- } \\
\text { M. palustre-M. nebraskense }\end{array}$ & $1,2,3,12$ & $\begin{array}{l}\text { Mycobacterium sp., not } \\
\text { M. haemophilum- } \\
\text { M. M. nebraskense }\end{array}$ \\
\hline M. haemophilum & 2 & $1,2,3,(9), 10,13$ & $\begin{array}{l}\text { M. malmoense-M. haemophilum- } \\
\text { M. palustre-M. nebraskense }\end{array}$ & $1,2,3,9,12$ & $\begin{array}{l}\text { M. haemophilum, } \\
\text { M. nebraskense, not } \\
\text { M. malmoense-M. palustre }\end{array}$ \\
\hline M. palustre & 2 & $1,2,3,10,13$ & $\begin{array}{l}\text { M. malmoense- } M \text {. haemophilum- } \\
M . \text { palustre-M. nebraskense }\end{array}$ & $1,2,3,12$ & $\begin{array}{l}\text { Mycobacterium sp., not } \\
\text { M. haemophilum- } \\
\text { M. nebraskense }\end{array}$ \\
\hline M. nebraskense ${ }^{g}$ & 1 & $1,2,3,10,13$ & $\begin{array}{l}\text { M. malmoense-M. haemophilum- } \\
\text { M. palustre, } M \text {. nebraskense }\end{array}$ & $1,2,3,9,12$ & $\begin{array}{l}\text { M. haemophilum, } \\
\quad \text { M. nebraskense, not } \\
\text { M. malmoense-M. palustre }\end{array}$ \\
\hline M. peregrinum & 2 & $1,2,3,14$ & $\begin{array}{l}\text { M. peregrinum-M. septicum- } \\
\text { M. alvei }\end{array}$ & $1,2,3$ & Mycobacterium sp. \\
\hline M. alvei & 2 & $1,2,3,14$ & $\begin{array}{l}\text { M. peregrinum-M. septicum- } \\
\text { M. alvei }\end{array}$ & $1,2,3$ & Mycobacterium sp. \\
\hline M. marinum & 2 & $1,2,3,10,15$ & M. marinum-M. ulcerans & $1,2,3,12$ & $\begin{array}{l}\text { Mycobacterium sp., not } \\
\text { M. ulcerans }\end{array}$ \\
\hline M. ulcerans & 2 & $1,2,3,10,15$ & M. marinum-M. ulcerans & $1,2,3,11,12$ & M. ulcerans \\
\hline M. xenopi & 3 & $1,2,3,(10), 17$ & M.xenopi & $1,2,3,(12)$ & Mycobacterium sp. \\
\hline M. simiae & 2 & $1,2,3$ & Mycobacterium sp. & $1,2,3,4,6$ & M. simiae \\
\hline M. mucogenicum & 3 & $1,2,3,10$ & Mycobacterium sp. & $1,2,3,5,12$ & M. mucogenicum \\
\hline M. smegmatis & 2 & $1,2,3$ & Mycobacterium sp. & $1,2,3,6,14$ & M. smegmatis \\
\hline M. goodii & 1 & $1,2,3$ & Mycobacterium sp. & $1,2,3,5,6,14$ & M. goodii \\
\hline M. celatum I and III & 2 & $1,2,3,10$ & Mycobacterium sp. & $1,2,3,6,12,14$ & M. celatum \\
\hline M. celatum II & 2 & $1,2,3,10$ & Mycobacterium sp. & $1,2,3,12$ & Mycobacterium sp. \\
\hline M. heckeshornense & 1 & $1,2,3$ & Mycobacterium sp. & $1,2,3,7,10,12$ & M. heckeshornense \\
\hline M. szulgai & 2 & $1,2,3,10$ & Mycobacterium sp. & $1,2,3,8,12$ & M. szulgai-M. intermedium \\
\hline M. intermedium & 1 & $1,2,3,10$ & Mycobacterium sp. & $1,2,3,8,12$ & M. szulgai-M. intermedium \\
\hline M. phlei & 2 & $1,2,3$ & Mycobacterium sp. & $1,2,3,8,16$ & M. phlei \\
\hline M. gastri & 1 & $1,2,3,10$ & Mycobacterium sp. & $1,2,3,12,(13)$ & M. gastri \\
\hline M. lentiflavum & 2 & $1,2,3$ & Mycobacterium sp. & $1,2,3,6,16$ & M. lentiflavum \\
\hline M. asiaticum & 3 & $1,2,3,10$ & Mycobacterium sp. & $1,2,3,12,15$ & M. asiaticum \\
\hline M. shimoidei & 2 & $1,2,3,10$ & Mycobacterium sp. & $1,2,3,12,16$ & M. shimoidei \\
\hline M. genavense & 2 & $1,2,3$ & Mycobacterium $\mathrm{sp}$. & $1,2,3,14,17$ & M. genavense \\
\hline M. neoaurum & 2 & $1,2,3,10$ & Mycobacterium sp. & $1,2,3,12$ & Mycobacterium sp. \\
\hline M. bohemicum & 2 & $1,2,10$ & $\mathrm{Gram}^{+}$, high $\mathrm{G}+\mathrm{C}$ content $^{j}$ & $1,2,12$ & $\mathrm{Gram}^{+}$, high $\mathrm{G}+\mathrm{C}$ content $^{j}$ \\
\hline M. sphagni & 1 & 1,2 & $\mathrm{Gram}^{+}$, high $\mathrm{G}+\mathrm{C}$ content $^{j}$ & $1,2,(6),(10)$ & $\mathrm{Gram}^{+}$, high $\mathrm{G}+\mathrm{C}$ content $^{j}$ \\
\hline M. gilvum & 2 & $1,2,3$ & Mycobacterium sp. & $1,2,3$ & Mycobacterium sp. \\
\hline $\begin{array}{l}\text { M. flavescens II- } \\
\text { M. novocastrense }\end{array}$ & 4 & $1,2,3$ & Mycobacterium $\mathrm{sp}$. & $1,2,3$ & Mycobacterium sp. \\
\hline M. elephantis-M. pulveris & 2 & 1,2 & $\mathrm{Gram}^{+}$, high $\mathrm{G}+\mathrm{C}$ content $^{j}$ & 1,2 & $\mathrm{Gram}^{+}$, high $\mathrm{G}+\mathrm{C}$ content $^{j}$ \\
\hline M. holsaticum & 1 & 1,2 & $\mathrm{Gram}^{+}$, high $\mathrm{G}+\mathrm{C}$ content $^{j}$ & 1,2 & $\mathrm{Gram}^{+}$, high $\mathrm{G}+\mathrm{C}$ content ${ }^{j}$ \\
\hline M. branderi & 1 & $1,2,3,10$ & Mycobacterium sp. & $1,2,3,12$ & Mycobacterium sp. \\
\hline M. nonchromogenicum & 1 & $1,2,3,10$ & Mycobacterium sp. & $1,2,3,12$ & Mycobacterium $\mathrm{sp}$. \\
\hline M. hassiacum & 3 & $1,2,3$ & Mycobacterium sp. & $1,2,3$ & Mycobacterium sp. \\
\hline M. triplex & 1 & $1,2,3$ & Mycobacterium sp. & $1,2,3$ & Mycobacterium sp. \\
\hline M. hiberniae & 1 & $1,2,3$ & Mycobacterium sp. & $1,2,3$ & Mycobacterium sp. \\
\hline M. diernhoferi & 1 & $1,2,3,10$ & Mycobacterium sp. & $1,2,3,12$ & Mycobacterium sp. \\
\hline M. tokaiense-M. murale & 1 & $1,2,3$ & Mycobacterium sp. & $1,2,3$ & Mycobacterium sp. \\
\hline M. kubicae & 1 & $1,2,3,10$ & Mycobacterium sp. & $1,2,3,12$ & Mycobacterium sp. \\
\hline
\end{tabular}


TABLE $1-$ Continued

\begin{tabular}{|c|c|c|c|c|c|}
\hline \multirow{2}{*}{$\begin{array}{l}\text { Mycobacterium } \\
\text { species }^{a}\end{array}$} & \multirow{2}{*}{$\begin{array}{l}\text { No. of } \\
\text { strains }\end{array}$} & \multicolumn{2}{|c|}{ GenoType CM results } & \multicolumn{2}{|c|}{ GenoType AS results } \\
\hline & & Band pattern ${ }^{k}$ & Identification & Band pattern ${ }^{k}$ & Identification \\
\hline M. thermoresistibile & 1 & $1,2,3,10$ & Mycobacterium sp. & $1,2,3,12$ & Mycobacterium sp. \\
\hline M. triviale & 1 & $1,2,3,10$ & Mycobacterium sp. & $1,2,3,12$ & Mycobacterium sp. \\
\hline M. chlorophenolicum & 1 & $1,2,3,10$ & Mycobacterium sp. & $1,2,3,12$ & Mycobacterium sp. \\
\hline M. heidelbergense & 1 & $1,2,(3), 10$ & Mycobacterium sp. & $1,2,(3), 12$ & Mycobacterium sp. \\
\hline M. chitae & 1 & $1,(2)$ & $\mathrm{Gram}^{+}$, high $\mathrm{G}+\mathrm{C}$ content $^{j}$ & $1,(2)$ & $\mathrm{Gram}^{+}$, high $\mathrm{G}+\mathrm{C}$ content $^{j}$ \\
\hline "M. engbaekii"" & 1 & $1,2,10$ & $\mathrm{Gram}^{+}$, high $\mathrm{G}+\mathrm{C}$ content ${ }^{j}$ & $1,2,12$ & $\mathrm{Gram}^{+}$, high $\mathrm{G}+\mathrm{C}$ content $^{j}$ \\
\hline M. terrae & 1 & $1,2,3,10$ & Mycobacterium sp. & $1,2,3,12$ & Mycobacterium sp. \\
\hline M. terrae group isolate ${ }^{g}$ & 3 & $1,2,(3), 10$ & Mycobacterium sp. & $1,2,3,12$ & Mycobacterium sp. \\
\hline M. parascrofulaceum ${ }^{g}$ & 1 & $1,2,3,9,10$ & M. scrofulaceum-"M. paraffinicum" & $1,2,3,12$ & Mycobacterium sp. \\
\hline $\begin{array}{l}\text { Mycobacterium sp. strain } \\
\text { MCRO6 }^{g}\end{array}$ & 2 & $1,2,3,10$ & Mycobacterium sp. & $1,2,3,12$ & Mycobacterium sp. \\
\hline $\begin{array}{l}\text { Mycobacterium sp. strain } \\
\text { IWGMT } 90174^{g}\end{array}$ & 1 & $1,2,10$ & Mycobacterium sp. & $1,2,12$ & Mycobacterium sp. \\
\hline $\begin{array}{l}\text { Mycobacterium sp. strain } \\
\text { IWGMT } 90242^{h}\end{array}$ & 2 & $1,2,3,10$ & Mycobacterium sp. & $1,2,3,12$ & Mycobacterium sp. \\
\hline M. triplex ${ }^{i}$-like & 1 & $1,2,10$ & Mycobacterium sp. & $1,2,12$ & Mycobacterium sp. \\
\hline "Mycobacterium sp. strain I5" & 1 & $1,2,3,10$ & Mycobacterium sp. & $1,2,3,6,10,12$ & M. celatum \\
\hline Corynebacterium amycolatum ${ }^{g}$ & 1 & 1,2 & $\mathrm{Gram}^{+}$, high $\mathrm{G}+\mathrm{C}$ content $^{j}$ & 1,2 & $\mathrm{Gram}^{+}$, high $\mathrm{G}+\mathrm{C}$ content $^{j}$ \\
\hline Nocardia novag & 1 & 1,2 & $\mathrm{Gram}^{+}$, high $\mathrm{G}+\mathrm{C}$ content $^{j}$ & 1,2 & $\mathrm{Gram}^{+}$, high $\mathrm{G}+\mathrm{C}$ content $^{j}$ \\
\hline Rhodococcus equi ${ }^{g}$ & 1 & 1,2 & $\mathrm{Gram}^{+}$, high $\mathrm{G}+\mathrm{C}$ content $^{j}$ & 1,2 & $\mathrm{Gram}^{+}$, high $\mathrm{G}+\mathrm{C}$ content $^{j}$ \\
\hline
\end{tabular}

${ }^{a}$ Strain identification is a result of 16S rRNA gene sequencing analysis (17), GenoType MTBC, and conventional biochemical tests.

${ }^{b}$ M. tuberculosis complex strains composed of M.tuberculosis $(n=3)$, M. bovis subsp. bovis $(n=3)$, M. bovis subsp. caprae $(n=2)$, M. bovis BCG $(n=2)$, M. africanum $(n=2)$, and $M$. microti $(n=2)$.

${ }^{c}$ M. avium strains composed of M. avium subsp. avium $(n=3)$ and M. avium subsp. paratuberculosis $(n=2)$.

${ }^{d}$ M. gordonae composed of M. gordonae I $(n=2)$, M. gordonae II $(n=4)$, and M. gordonae III $(n=1)$.

${ }^{e} M$. intracellulare composed of $M$. intracellulare $(n=4), M$. intracellulare serotype $7(n=1)$, and $M$. intracellulare serotype $18(n=2)$

${ }^{f}$ M. kansasii composed of M. kansasii sequevars I $(n=1)$, I or IV $(n=2)$, and II $(n=1)$.

${ }^{g}$ Strain identification based on sequencing of the first 500 bp of the $16 \mathrm{~S}$ rRNA gene: "M. engbaekii" (accession number X88919), $M$. terrae group isolate (accession number AY215363), M. parascrofulaceum (accession number AF152559), MCRO6 (accession number X93032), Mycobacterium IWGMT 90174 (accession number X88908), "Mycobacterium sp. strain I5" (accession number AY177352), Nocardia nova (accession number AY191250), Corynebacterium amycolatum (accession number AY831726), and Rhodococcus equi (Corynebacterium equi) (accession number X80614).

${ }^{h}$ Mycobacterium sp. strain IWGMT 90242 (accession number X88919) $(n=2)$.

${ }^{i}$ The first 500 bp of the 16S rRNA gene are identical to those of Mycobacterium triplex (accession number AY215367), except for two T-C exchanges at bp 202 and 265 (Escherichia coli numbering system).

${ }^{j}$ Detection of mycobacteria and gram-positive bacteria with a high $\mathrm{G}+\mathrm{C}$ content in their DNA.

${ }^{k}$ Brackets, band sometimes missing; parentheses, signal of minor intensity.

Genotypic characterization. Samples included in the study were selected by routine identification testing of mycobacteria. They were derived from different culture media (liquid or solid). From solid medium, one loopful of cells was suspended in $400 \mu \mathrm{l}$ of distilled water, boiled for $20 \mathrm{~min}$, and sonicated for 15 min. Cells from liquid medium were prepared in the same way but with a preceding centrifugation step. For this, $1 \mathrm{ml}$ of liquid culture medium was centrifuged $(10,000 \times g, 15 \mathrm{~min}$, room temperature $)$, the supernatant was discarded, and the pellet was suspended in 300 to $500 \mu \mathrm{l}$ of distilled water. All of the samples were stored at $-20^{\circ} \mathrm{C}$ before further use.

The samples were analyzed by DNA sequencing of the first $500 \mathrm{bp}$ of the $5^{\prime}$ region of the 16S rRNA gene as described by Richter and colleagues (17). If identification on the basis of differences in the 16S rRNA gene sequence was not possible, additional analysis of the $h s p 65$ gene (27) or the presence of a specific insertion element was performed (23). M. tuberculosis complex strains were differentiated by the GenoType MTBC assay (Hain Lifescience GmbH, Nehren, Germany).

GenoType CM/AS assay. The GenoType Mycobacterium CM/AS assay was performed as recommended by the manufacturer. Briefly, for amplification $35 \mu \mathrm{l}$ of a primer-nucleotide mixture (provided with the kit), amplification buffer containing $2.5 \mathrm{mM} \mathrm{MgCl}_{2}, 1.25 \mathrm{U}$ of hot start Taq polymerase (QIAGEN, Hilden, Germany), and $5 \mu \mathrm{l}$ of the heat-inactivated suspension in a final volume of $50 \mu \mathrm{l}$ was used. The amplification protocol consisted of $15 \mathrm{~min}$ of denaturing at $95^{\circ} \mathrm{C}$, followed by 10 cycles comprising $30 \mathrm{~s}$ at $95^{\circ} \mathrm{C}$ and $120 \mathrm{~s}$ at $58^{\circ} \mathrm{C}$, an additional 20 cycles comprising $25 \mathrm{~s}$ at $95^{\circ} \mathrm{C}, 40 \mathrm{~s}$ at $53^{\circ} \mathrm{C}$, and $40 \mathrm{~s}$ at $70^{\circ} \mathrm{C}$, and a final extension at $70^{\circ} \mathrm{C}$ for $8 \mathrm{~min}$ Hybridization and detection were performed in an automated washing and shaking device (Profiblot; Tekan, Maennedorf, Switzerland). The program was started after mixing $20 \mu \mathrm{l}$ of the amplification products with $20 \mu \mathrm{l}$ of denaturing reagent (provided with the kit) for $5 \mathrm{~min}$ in separate troughs of a plastic well. Automatically, $1 \mathrm{ml}$ of prewarmed hybridization buffer was added, followed by a stop to put the membrane strips into each trough. The hybridization procedure was performed at $45^{\circ} \mathrm{C}$ for $0.5 \mathrm{~h}$, followed by two washing steps. For colorimetric detection of hybridized amplicons, streptavidin conjugated with alkaline phosphatase and substrate buffer was added. After a final washing, strips were air dried and fixed on paper. Each CM and AS strip contains 17 probes including amplification and hybridization controls to verify the test procedures (Fig. 1). With the CM assay, 15 patterns can be obtained from 23 species (10 individually and 13 in combination), and with the AS assay, 16 patterns can be obtained from 18 species (12 individually and 2 in combination). In the cases of M. marinum and M. ulcerans, the CM assay shows the same pattern for the two species, but with the serial use of the AS assay the two species can be resolved (Fig. 2). The M. marinum-M. ulcerans pattern in the CM assay was counted as a pattern representing individual species, since it can be resolved with the AS test. A total of 23 patterns attributable to 22 individual species and 8 patterns representing 15 species in combinations of 2 to 4 species can be obtained. In addition, each assay includes two patterns with an amplification control specific for the genus Mycobacterium and one for the detection of all known mycobacteria and members of the group of gram-positive bacteria with a high $\mathrm{G}+\mathrm{C}$ content.

Evaluation of the assays was accomplished with a beta version of the kit. In the now commercially available version, the banding pattern was rearranged in order to avoid misinterpretation of identical results of the CM and AS assays. After rechecking of selected samples, we adapted our results to the current interpretation chart.

\section{RESULTS}

In this study, 156 clinical isolates composed of 83 different species isolated in Germany between 1999 and 2004 were included. The CM/AS assay is based on a multiplex PCR targeting species-specific DNA regions combined with a reverse hybridization format (DNA strip). The specific patterns are composed of obligatory and additional facultative stainings that can be visually identified by clear-cut hybridization signals on the membrane strips (Fig. 1). Examples of typical test results are shown in Fig. 2. Whereas the CM assay allows the identification of at least the most relevant mycobacterial spe- 
(A)

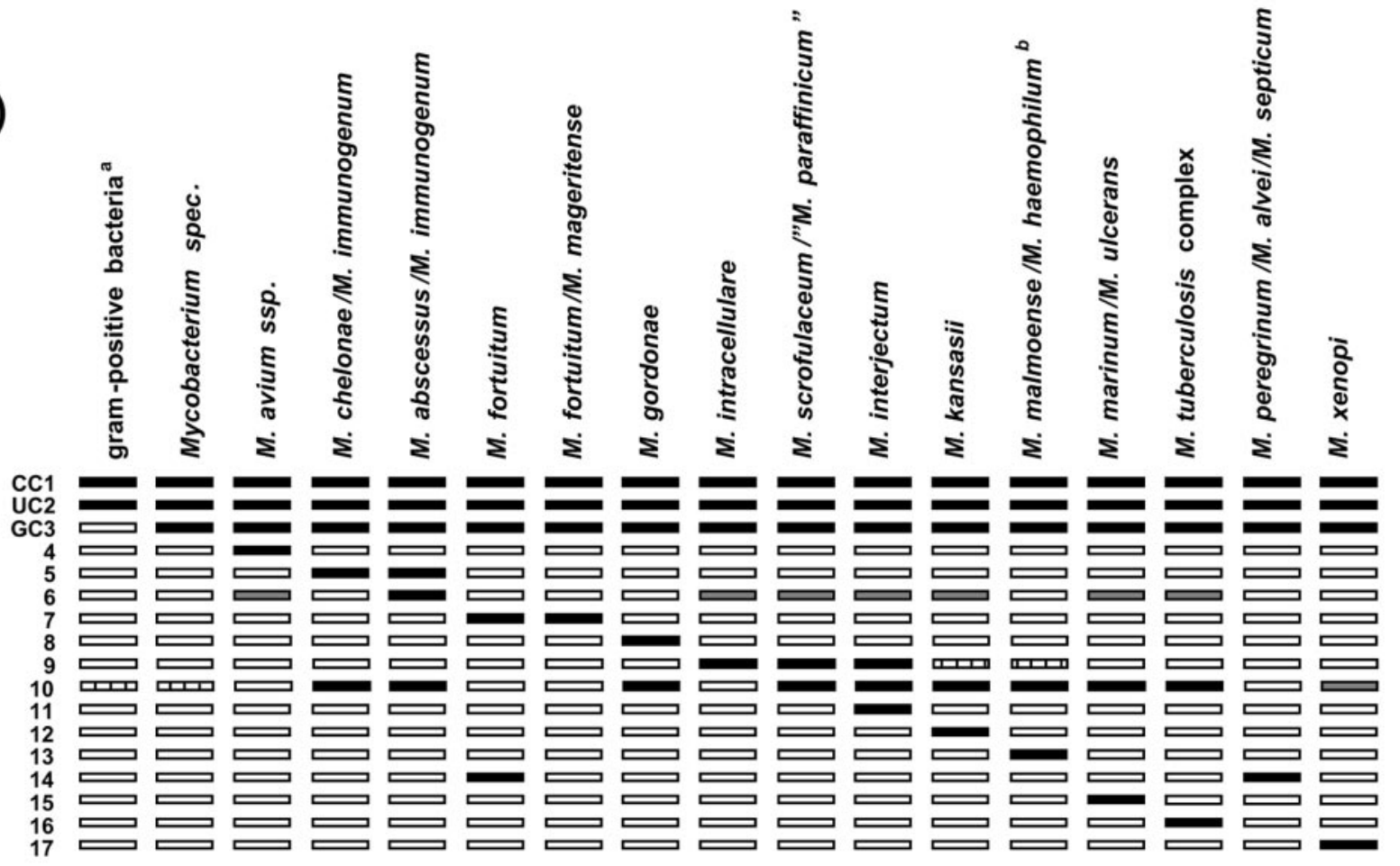

(B)

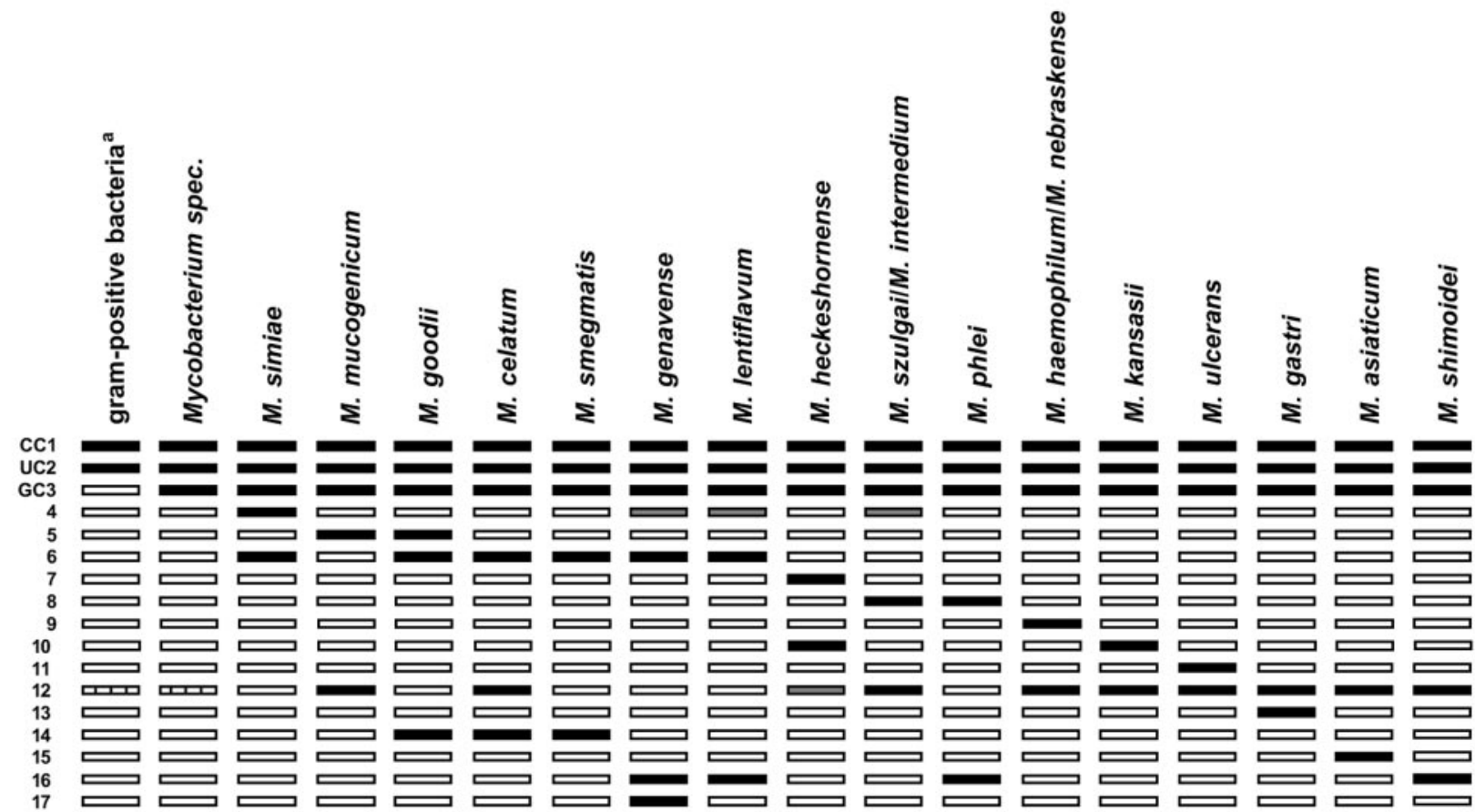

FIG. 1. Interpretation chart for the Genotype CM (A) and AS (B) assays. The specificities of the lines are (from top to bottom) as follows: 1, conjugate control (CC); 2, universal control (UC); 3, genus control (GC); 4 to 17, specific probes for the identification of individual and combined mycobacterial species. Superscripts: a, gram-positive bacteria with a high G+C content in their DNA; b, also identical pattern for M. palustre and M. nebraskense. Filled boxes, staining; striped boxes, facultative staining; gray boxes, facultative weak staining; blank boxes, no staining.

cies, the AS assay is designed to identify further mycobacterial species.

For 151 out of 156 strains, an interpretable result was obtained after performing the CM and AS assays. Five strains (one strain each of $M$. kansasii, M. mucogenicum, M. interjectum, M. heckeshornense, and M. genavense) showed neither a positive conjugate control line, nor the universal control line, nor species-specific lines. Since at least the conjugate control 


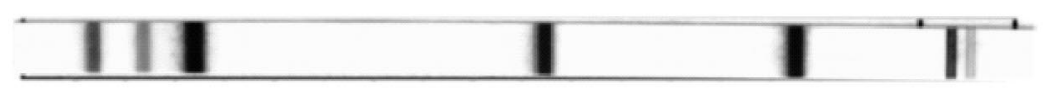

GenoType CM: M. marinum/ulcerans

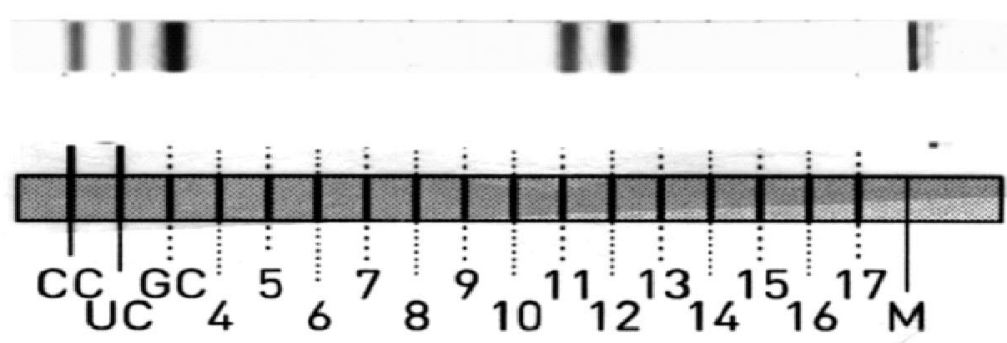

\section{GenoType AS: M. ulcerans}

FIG. 2. Identification of M. ulcerans by serial use of the GenoType CM and AS assays. With the banding pattern of the GenoType CM assay, either M. ulcerans or M. marinum can be identified; by subsequent use of the GenoType AS, the isolate can be further differentiated as M. ulcerans. $\mathrm{CC}$, conjugate control; UC, universal control; GC, genus control; M, marker for orientation on the strip.

and the universal control line must be positive for a valid result, these five strains were excluded. For all other strains, each band number, which was positive on the CM or AS strip, was noted and the patterns were evaluated to determine the Mycobacterium species according to the interpretation chart provided by the manufacturer (Fig. 1 and Table 1).

Results of the CM assay. Of 76 strains for which a specific pattern was expected with the CM assay, 74 strains (97.4\%) developed the expected pattern (Table 1). Only two substrains (M. intracellulare serovar 7 and $M$. kansasii sequevar VI) were not correctly identified by the $\mathrm{CM}$ assay. For those strains which were not expected to yield a specific pattern by the assay, the correct result was obtained for $66(88.0 \%)$ out of 75 strains. Mycobacterium sp. strain IWGMT 90242, an M. avium-like strain (31), was correctly negative for the $M$. avium and $M$. intracellulare probes and only identified as Mycobacterium sp. For M. parascrofulaceum, a species closely related to M. scrofulaceum, a false result (CM pattern, M. scrofulaceum-"M. paraffinicum") was achieved (Table 1). For eight strains (six species), recognition as mycobacterial species failed since these strains were only recognized as members of the group of grampositive bacteria with a high $\mathrm{G}+\mathrm{C}$ content in their DNA but not as mycobacteria species characterized by specific band 3 . The three nonmycobacterial species tested were correctly identified as gram-positive bacteria.

Results of the AS assay. Of the 28 strains included in this study that were expected to produce specific individual or combined patterns in the AS test, 26 strains (92.9\%) showed the expected patterns (Table 1$)$. Whereas M. celatum I and III strains were correctly reactive with the specific $M$. celatum probes, the two M. celatum II strains were negative. With the AS assay, the definite identification of $M$. marinum and $M$. ulcerans could be resolved by a specific probe reacting with $M$. ulcerans but not with $M$. marinum (Fig. 2). In the case of an $M$. marinum strain, the omission of the M. ulcerans band indicates the presence of $M$. marinum. Further differentiation of the $M$. haemophilum-M.nebraskense-M. malmoense-M.palustre group is possible with a specific probe of the AS assay reacting with $M$. haemophilum and M. nebraskense only and not with $M$. malmoense or M. palustre.
The results of the AS assay for species that are identifiable with the CM assay only should be Mycobacterium sp. This was obtained for 110 out of 123 strains. One $M$. fortuitum strain missed specific band 3, the genus control, and was thus identified as a gram-positive bacterium with a high $\mathrm{G}+\mathrm{C}$ content but not as a Mycobacterium sp. Furthermore, a weak hybridization signal for $M$. smegmatis could be observed with this strain, which may be explained by crosshybridization. However, because of the instructions of the manufacturer, the signal was too weak for validation. The only species that is identifiable by both tests is M. kansasii. Whereas most of the subspecies could be clearly identified as M. kansasii also in the AS assay, strains of M. kansasii sequevars VI and III reacted with probes other than that specific for M. kansasii. These results were attributable to neither $M$. kansasii nor another species. One M. kansasii sequevar VI strain showed only a very weak signal with the M. kansasii probes (not validated). For those strains which are not expected to yield a specific pattern by the AS assay, the correct result was obtained for $66(88.0 \%)$ out of 75 strains. For one not validly described mycobacterial species ("Mycobacterium sp. strain I5"), a false result (AS pattern, M. celatum) was achieved (Table 1). In eight strains (six species) that were not recognized as Mycobacterium sp. by the CM assay, recognition as mycobacterial species also failed with the AS assay as these strains were only identified as members of the group of gram-positive bacteria with a high $\mathrm{G}+\mathrm{C}$ content in their DNA. However, the three nonmycobacterial species tested were correctly identified as gram-positive bacteria.

\section{DISCUSSION}

Early and reliable identification of mycobacteria may provide patients with an earlier onset of proper treatment and may spare patients from unnecessary treatment in the case of growth of environmental species. The conventional biochemical procedures are unable to distinguish more than 100 mycobacterial species since they have overlapping phenotypic patterns $(22,28)$. Because of the increasing data on numerous 
genes available for mycobacterial species, differentiation of all species is achievable on the level of DNA sequences. Therefore, efforts for the development of new diagnostic tools for the identification of mycobacterial species by using sequencebased molecular techniques have been undertaken in recent years $(3,4,6,10,11,21,26,27,29)$. These techniques advanced the speed and effectiveness of identification of mycobacterial species grown from clinical specimens.

In this study, we evaluated the GenoType Mycobacterium $\mathrm{CM} / \mathrm{AS}$ assay, which is intended for the identification of 23 and 14 mycobacterial species either as individual species or in combination with others. In order to test a broad variety of species, 67 different mycobacterial strains (61 validly published species and subspecies and 6 not validly published species) and 3 nonmycobacterial but closely related species were tested. For $92.6 \%$ and $89.9 \%$ of the isolates, concordant results could be achieved with the CM and AS assays, respectively. Only individual substrains of two species (M. intracellulare serovar 7 and M. kansasii sequevar VI) were not identified by the tests but still identified as mycobacteria. Both species are known for their broad genetic variability $(1,24)$. However, with the $\mathrm{CM} / \mathrm{AS}$ assay, the most common clinical isolates of these groups were identified. For instance, $M$. kansasii sequevar I represents the most common clinical isolate from humans (1, 25 ) and also in our laboratory the majority of the clinical strains identified belong to M. kansasii sequevar I. M. kansasii sequevars III, IV, and V have been isolated much less commonly from humans but have been found in environmental samples $(1,12,32)$. Concerning $M$. intracellulare subspecies, frequencies of isolated strains differ markedly and $M$. intracellulare serovar 7 belongs to the rarer isolates found in human specimens (18). Thus, with the CM/AS assay, most of the subspecies were correctly identified through a single banding pattern so that further differentiation with specific probes is not necessary and does not impair the applicability of the test. Subspecies not identified by the assay were at least not classified incorrectly so that the correct final result would be found with subsequent techniques.

A strain that was not recognized by the CM/AS assay but only identified as a Mycobacterium sp. was M. celatum II. This result was not surprising since this strain differs from the other M. celatum I and III strains in the 16S RNA gene sequence and other genetic markers $(2,13)$. The discrepancy in the CM/AS assay will be included in future in the manual supplied with the assay (personal communication from the manufacturer). Furthermore, we could show in our study that most of the mycobacterial or other species that cannot be recognized by the $\mathrm{CM} / \mathrm{AS}$ assay were correctly identified as Mycobacterium $\mathrm{sp}$. or gram-positive bacteria with a high $\mathrm{G}+\mathrm{C}$ content. However, eight strains (six species) were identified only as gram-positive bacteria with a high $\mathrm{G}+\mathrm{C}$ content and failed to be specified as mycobacterial species with both assays. Thus, evidence of gram-positive bacteria with a high $\mathrm{G}+\mathrm{C}$ content does not exclude the concomitance of mycobacteria and has to be evaluated carefully.

The only truly incorrect result that was obtained was the misidentification of a strain not validly published, "Mycobacterium sp. strain I5," as $M$. celatum, which should be rated as a failure of the assay because of a cross-reaction. Similar discrepancies cannot be excluded because of the broad variety of known and not-yet-known mycobacteria with different DNA sequences in the targeted region. Another fact that should be mentioned is the occurrence of weak background bandings that we observed in some cases. For instance, one $M$. fortuitum strain correctly identified by the CM assay developed background bandings with the AS assay, which are, however, not assessable according to the instructions of the manufacturer. Nevertheless, this can lead to uncertainty, since an M. kansasii sequevar VI strain also showed weak bands with the AS assay; in this case, they were correct but also not assessable because of their weakness.

Another limitation of the test is the resolution of patterns which represent more than one species, which necessitates other techniques for further discrimination, e.g., biochemical tests, leading to a delay in obtaining a result. Mainly, a species like M. malmoense is rather difficult to identify by other than molecular techniques. If differentiation is desired, DNA analysis of an appropriate target is indispensable.

Recently, in a multicountry survey with 14 participating countries, the frequencies of isolated nontuberculous mycobacteria from clinical laboratories were estimated over a 20year period. The mycobacterial species most frequently isolated in 1991 to 1996 were the $M$. avium-M. intracellulare complex (29.1\%), M. gordonae (18.8\%). M. xenopi (19\%), M. kansasii (10.3\%), and M. fortuitum (9.8\%), accounting for $87.6 \%$ of all nontuberculous mycobacteria (8). The CM assay is able to identify all of these isolates. Thus, together with the other species included on the strips, the CM assay could have identified an estimated $96.4 \%$ of the isolates to the species level and a further $0.9 \%$ could have been identified with the subsequent AS assay. Therefore, it can be estimated that only a few cases of unusual or unknown mycobacteria will remain unidentified to the species level. Because of the genus probe, these strains can still be identified as mycobacteria or at least as gram-positive bacteria with a high $\mathrm{G}+\mathrm{C}$ content. If correct identification to the species level is required, however, DNA sequencing in these rare cases of respective gene fragments is indispensable.

In conclusion, the CM/AS assay allows rapid and specific detection of the most frequently isolated and most relevant species in a mycobacterial diagnostic laboratory. Identification of 37 species (22 individually and 15 as combinations of species) in a sequential analysis represents an important improvement. Moreover, with the sequential application of two different assays the balance between technical feasibility and a high rate of detection of different species is optimal. The clinical performance of these tests may also depend on the prevalence and frequency of nontuberculous mycobacterial species isolated in different countries, and this diversity should therefore be estimated before the test can be implemented as a routine application.

Both the PCR technology and the reverse hybridization technique used for the test have been proven to be robust and reproducible. The results are easy to interpret without extensive expertise such as that required for the application and interpretation of biochemical tests or DNA sequencing. Furthermore, it can easily be implemented in routine work flow, especially when other strip assays are already established, such as the GenoType MTBC for identification and differentiation of the $M$. tuberculosis complex $(15,16)$ or the 
GenoType MTBDR assay for the detection of mutations that are associated with resistance to rifampin and isoniazid (5). All tests can be run by using the same platform technology. Our results indicate that the CM and AS assays are very useful for the rapid and accurate discrimination of mycobacteria from clinical isolates in a routine mycobacteriological laboratory.

\section{ACKNOWLEDGMENTS}

We thank F. Schaefer and B. Schlüter, Forschungszentrum Borstel, Borstel, Germany, for excellent technical assistance and Hain Lifescience, Nehren, Germany, for providing the GenoType assays.

\section{REFERENCES}

1. Alcaide, F., I. Richter, C. Bernasconi, B. Springer, C. Hagenau, R. SchulzeRöbbecke, E. Tortoli, R. Martín, E. C. Böttger, and A. Telenti. 1997. Heterogeneity and clonality among isolates of Mycobacterium kansasii: implications for epidemiological and pathogenicity studies. J. Clin. Microbiol. 35: 1959-1964.

2. Butler, W. R., S. P. O'Connor, M. A. Yakrus, R. W. Smithwick, B. B. Plikaytis, C. W. Moss, M. M. Floyd, C. L. Woodley, J. O. Kilburn, F. S. Vadney, and W. M. Gross. 1993. Mycobacterium celatum sp. nov. Int. J. Syst. Bacteriol. 43:539-548.

3. Cloud, J. L., H. Neal, R. Rosenberry, C. Y. Turenne, M. Jama, D. R. Hillyard, and K. C. Carroll. 2002. Identification of Mycobacterium spp. by using a commercial $16 \mathrm{~S}$ ribosomal DNA sequencing kit and additional sequencing libraries. J. Clin. Microbiol. 40:400-406.

4. Harmsen, D., S. Dostal, A. Roth, S. Niemann, J. Rothganger, M. Sammeth, J. Albert, M. Frosch, and E. Richter. 2003. RIDOM: comprehensive and public sequence database for identification of Mycobacterium species. BMC Infect. Dis. 3:26

5. Hillemann, D., M. Weizenegger, T. Kubica, E. Richter, and S. Niemann 2005. Use of the GenoType MTBDR assay for rapid detection of rifampin and isoniazid resistance in Mycobacterium tuberculosis complex isolates. J. Clin. Microbiol. 8:3699-3703.

6. Khan, I. U., and J. S. Yadav. 2004. Development of a single-tube, cell lysis-based, genus-specific PCR method for rapid identification of mycobacteria: optimization of cell lysis, PCR primers and conditions, and restriction pattern analysis. J. Clin. Microbiol. 42:453-457.

7. Makinen, J., A. Sarkola, M. Marjamaki, M. K. Viljanen, and H. Soini. 2002. Evaluation of GenoType and LiPA MYCOBACTERIA assays for identification of Finnish mycobacterial isolates. J. Clin. Microbiol. 40 3478-3481.

8. Martin-Casabona, N., A. R. Bahrmand, J. Bennedsen, V. O. Thomsen, M. Curcio, M. Fauville-Dufaux, K. Feldman, M. Havelkova, M. L. Katila, K Koksalan, M. F. Pereira, F. Rodrigues, G. E. Pfyffer, F. Portaels, J. R. Urgell, S. Rüsch-Gerdes, E. Tortoli, V. Vincent, and B. Watt for the Spanish Group for Non-Tuberculosis Mycobacteria. 2004. Non-tuberculous mycobacteria: patterns of isolation. A multi-country retrospective survey. Int. J. Tuberc. Lung Dis. 8:1186-1193.

9. Padilla, E., V. González, J. M. Manterola, A. Pérez, M. D. Quesada, S. Gordillo, C. Vilaplana, M. A. Pallarés, S. Molinos, M. D. Sánchez, and V. Ausina. 2004. Comparative evaluation of the new version of the INNO-LiPA Mycobacteria and GenoType Mycobacterium assays for identification of Mycobacterium species from MB/BacT liquid cultures artificially inoculated with mycobacterial strains. J. Clin. Microbiol. 42:3083-3088.

10. Park, H., H. Jang, E. Song, C. L. Chang, M. Lee, S. Jeong, J. Park, B. Kang, and C. Kim. 2005. Detection and genotyping of Mycobacterium species from clinical isolates and specimens by oligonucleotide array. J. Clin. Microbiol. 43:1782-1788

11. Pauls, R. J., C. Y. Turenne, J. N. Wolfe, and A. Kabani. 2003. A high proportion of novel mycobacteria species identified by $16 \mathrm{~S}$ rDNA analysis among slowly growing AccuProbe-negative strains in a clinical setting. Am. J Clin. Pathol. 120:560-566.

12. Picardeau, M., G. Prod'hom, L. Raskine, M. P. LePennec, and V. Vincent. 1997. Genotypic characterization of five subspecies of Mycobacterium kansasii. J. Clin. Microbiol. 35:25-32.

13. Picardeau, M., T. J. Bull, G. Prod'hom, A. L. Pozniak, D. C. Shanson, and V. Vincent. 1997. Comparison of a new insertion element, IS1407, with established molecular markers for the characterization of Mycobacterium celatum. Int. J. Syst. Bacteriol. 47:640-644.
14. Primm, T. P., C. A. Lucero, and J. O. Falkinham III. 2004. Health impacts of environmental mycobacteria. Clin. Microbiol. Rev. 17:98-106.

15. Richter, E., M. Weizenegger, A. M. Fahr, and S. Rüsch-Gerdes, 2004. Usefulness of the GenoType MTBC assay for differentiating species of the Mycobacterium tuberculosis complex in cultures obtained from clinical specimens. J. Clin. Microbiol. 42:4303-4306.

16. Richter, E., M. Weizenegger, S. Rüsch-Gerdes, and S. Niemann. 2003. Evaluation of GenoType MTBC assay for differentiation of clinical Mycobacterium tuberculosis complex isolates. J. Clin. Microbiol. 41:2672-2675.

17. Richter, E., S. Niemann, F. O. Gloeckner, G. E. Pfyffer, and S. RüschGerdes. 2002. Mycobacterium holsaticum sp. nov. Int. J. Syst. Evol. Microbiol. 52:1991-1996.

18. Saad, M. H. F., V. Vincent, D. J. Dawson, M. Palaci, L. Ferrazoli, and L. S. Fonseca. 1997. Analysis of Mycobacterium avium complex serovars isolated from AIDS patients from southeast Brazil. Mem. Inst. Oswaldo Cruz 92: $471-475$.

19. Sarkola, A., J. Makinen, M. Marjamaki, H. J. Marttila, M. K. Viljanen, and H. Soini. 2004. Prospective evaluation of the GenoType assay for routine identification of mycobacteria. Eur. J. Clin. Microbiol. Infect. Dis. 23:642645 .

20. Scarparo, C., P. Piccoli, A. Rigon, G. Ruggiero, D. Nista, and C. Piersimoni. 2001. Direct identification of mycobacteria from MB/BacT Alert 3D bottles: comparative evaluation of two commercial probe assays. J. Clin. Microbiol. 39:3222-3227.

21. Shrestha, N. K., M. J. Tuohy, G. S. Hall, U. Reischl, S. M. Gordon, and G. W. Procop. 2003. Detection and differentiation of Mycobacterium tuberculosis and nontuberculous mycobacterial isolates by real-time PCR. J. Clin. Microbiol. 41:5121-5126.

22. Somoskovi, A., J. Mester, Y. M. Hale, L. M. Parsons, and M. Salfinger. 2002. Laboratory diagnosis of nontuberculous mycobacteria. Clin. Chest Med. 23:585-597.

23. Stinear, T., B. C. Ross, J. K. Davies, L. Marino, R. M. Robins-Browne, F. Oppedisano, A. Sievers, and P. D. R. Johnson. 1999. Identification and characterization of IS2404 and IS2606: two distinct repeated sequences for detection of Mycobacterium ulcerans by PCR. J. Clin. Microbiol. 37:10181023.

24. Swanson, D. S., V. Kapur, K. Stockbauer, X. Pan, R. Frothingham, and J. M. Musser. 1997. Subspecific differentiation of Mycobacterium avium complex strains by automated sequencing of a region of the gene (hsp65) encoding a 65-kilodalton heat shock protein. Int. J. Syst. Bacteriol. 47:414-419.

25. Taillard, C., G. Greub, R. Weber, G. E. Pfyffer, T. Bodmer, S. Zimmerli, R. Frei, S. Bassetti, P. Rohner, J.-C. Piffaretti, E. Bernasconi, J. Bille, A. Telenti, and G. Prod'hom. 2003. Clinical implications of Mycobacterium kansasii species heterogeneity: Swiss national survey. J. Clin. Microbiol. 41:1240-1244.

26. Taylor, T. B., C. Patterson, Y. Hale, and W. W. Safranek. 1997. Routine use of PCR-restriction fragment length polymorphism analysis for identification of mycobacteria growing in liquid media. J. Clin. Microbiol. 35:79-85.

27. Telenti, A., F. Marchesi, M. Balz, F. Bally, E. C. Böttger, and T. Bodmer. 1993. Rapid identification of mycobacteria to the species level by polymerase chain reaction and restriction enzyme analysis. J. Clin. Microbiol. 31:175178 .

28. Tortoli, E., A. Bartoloni, E. C. Böttger, S. Emler, C. Garzelli, E. Magliano, A. Mantella, N. Rastogi, L. Rindi, C. Scarparo, and P. Urbano. 2001. Burden of unidentifiable mycobacteria in a reference laboratory. J. Clin. Microbiol. 39:4058-4065.

29. Tuohy, M. J., G. S. Hall, M. Sholtis, and G. W. Procop. 2005. Pyrosequencing as a tool for the identification of common isolates of Mycobacterium sp. Diagn. Microbiol. Infect. Dis. 51:245-250.

30. Wallace, R. J., Jr., B. A. Brown, and D. E. Griffith. 1998. Nosocomial outbreaks/pseudo-outbreaks caused by nontuberculous mycobacteria. Annu. Rev. Microbiol. 52:453-490.

31. Wayne, L. G., R. C. Good, E. C. Böttger, R. Butler, M. Dorsch, T. Ezaki, W. Gross, V. Jonas, J. Kilburn, P. Kirschner, M. I. Krichevsky, M. Ridell, T. M. Shinnick, B. Springer, E. Stackebrandt, I. Tarnok, H. Tasaka, V. Vincent, N. G. Warren, C. A. Knott, and R. Johnson. 1996. Semantide- and chemotaxonomy-based analysis of some problematic phenotypic clusters of slowly growing mycobacteria, a cooperative study of the International Working Group on Mycobacterial Taxonomy. Int. J. Syst. Bacteriol. 46:280-297.

32. Zhang, Y., L. B. Mann, R. W. Wilson, B. A. Brown-Elliott, V. Vincent, Y. Iinuma, and R. J. Wallace, Jr. 2004. Molecular analysis of Mycobacterium kansasii isolates from the United States. J. Clin. Microbiol. 42:119125 